\title{
Detection of tetragonal zirconia in alumina-zirconia powders by thermoluminescence
}

\section{Christian Sallé(1), Philippe Grosseau ${ }^{(1) *}$, Guilhot Bernard ${ }^{(2)}$, Philibert IACCONI $^{(3)}$, MOURAD BENABDESSELAM(3) , GILLES FANTOZZI ${ }^{(4)}$}

(1) Ecole Nationale Supérieure des Mines de Saint Etienne, Centre SPIN ; Département PMMC ; LPMG, UMR CNRS 5148, 158 Cours Fauriel ; 42023 Saint-Étienne Cedex 2, France

(2) Université de Nice-Sophia Antipolis, LPES, EA1174, Parc Valrose, o6108, Nice Cedex 2, France

(3) Institut National des Sciences Appliquées, GEMPPM, CNRS-UMR 5510, 20, avenue Albert Einstein, F-69621, Villeurbanne Cedex, France

\begin{abstract}
The thermoluminescence (TL) after excitation by UV or X-rays radiation of alumina-zirconia powders is investigated. The composites present five of the characteristic peaks of zirconia at $-170,-145,-90,0$ and $95{ }^{\circ} \mathrm{C}$. After a thermal treatment of mixed oxides, a new peak is observed at $-35^{\circ} \mathrm{C}$ in TL. This peak reveals the presence of stabilized tetragonal zirconia in the material. Moreover by comparing this analysis with those realised by X-ray diffraction (XRD), it can by shown that the TL has one better limit of detection than the XRD.
\end{abstract}

Keywords:

$\mathrm{Al}_{2} \mathrm{O}_{3}$; Composites; Defects; Thermoluminescence; $\mathrm{ZrO}_{2}$

\section{Introduction}

The objective of this work is to show that the thermoluminescence (TL) allows the detection of the zirconia tetragonal phase in the alumina matrix with a higher sensitivity than the X-rays diffraction technique (XRD). In order to discuss if we have the right conditions to favour the presence of the tetragonal phase of zirconia in our composites, we need to call back some well-known results on the appearance of the tetragonal phase, and its behaviour in the alumina matrix.

Zirconia $\left(\mathrm{ZrO}_{2}\right)$ is monoclinic $\left(\mathrm{m}-\mathrm{ZrO}_{2}\right)$ below $1170{ }^{\circ} \mathrm{C}$, tetragonal $\left(\mathrm{t}-\mathrm{ZrO}_{2}\right)$ up to $2370{ }^{\circ} \mathrm{C}$, and then cubic $\left(\mathrm{c}-\mathrm{ZrO}_{2}\right)$ at high temperature up to the melting point $\left(2680{ }^{\circ} \mathrm{C}\right) \cdot[1]$

The tetragonal $\rightarrow$ monoclinic $(\mathrm{t} \rightarrow \mathrm{m})$ phase transformation is martensitic [2] and has been widely studied because of its anisotropic behaviour and of the large volume increase (between 3 and 5\%) which is involved [3].

This transformation can be used for the strengthening of $\mathrm{Al}_{2} \mathrm{O}_{3}-\mathrm{ZrO}_{2}$ composites ("transformation toughening"). This toughening can by due either to the transformation toughening or micro-cracking, depending on the size, amount and solute content of zirconia particles [4].

\footnotetext{
"Corresponding author : grosseau@emse.fr
} 
The presence of zirconia particles, for an amount of $\mathrm{ZrO}_{2}$ equal to 5 vol.\% at least,[5 and 6] limits the abnormal grain growth of alumina during the sintering of the material. In $\mathrm{Al}_{2} \mathrm{O}_{3}-\mathrm{ZrO}_{2}$ composites, the tetragonal phase is stable at room temperature only if the zirconia grain size lies between two critical values (from about $0.1 \mu \mathrm{m}$ up to $0.5 \mu \mathrm{m}$ ), which depend on strains in the alumina matrix and on the amount of zirconia.[7] The fraction of tetragonal phase increases when the quantity of zirconia decreases (30\% of tetragonal phase for 5 vol.\% of $\mathrm{ZrO}_{2}$, but only $5 \%$ of tetragonal phase for $20 \mathrm{vol} . \%$ of $\mathrm{ZrO}_{2}$ ) [8 and 9].

\section{Experimental procedure}

$\gamma$-Alumina used in this study is a commercial powder supplied by Baikowski Chimie, France, and synthesised by thermal decomposition of ammonium alum $\left(\mathrm{NH}_{4} \mathrm{Al}\left(\mathrm{SO}_{4}\right)_{2} \cdot 12 \mathrm{H}_{2} \mathrm{O}\right)$, process used to produce highly pure alumina $\left(>99.99 \% \mathrm{Al}_{2} \mathrm{O}_{3}\right)$. Then $\alpha$-alumina is obtained by a thermal treatment of $\gamma$-alumina at $1400^{\circ} \mathrm{C}$ under controlled atmosphere (oxygen).

The zirconia is a commercial powder (supplied by Rhône-Alpes Chimie, France) and its purity is higher than $99 \%$. XRD analysis shows that this zirconia powder exists in the form of monoclinic phase (baddeleyite). The mixtures of oxides, $\alpha-\mathrm{Al}_{2} \mathrm{O}_{3}$ and $\mathrm{ZrO}_{2}$, were wet ground in an organic solvent (acetone), with continuous stirring. Various mixtures are used: 1, 5, $10 . . . w t . \%$ of $\mathrm{ZrO}_{2}$. Five grams of each mixture were prepared. Then half part of these mixtures undergoes a thermal treatment under controlled atmosphere (oxygen), in order to reveal and study, by the techniques of X-ray diffraction and thermoluminescence, the effect of doping by zirconia on the alumina crystalline structure. This treatment is conducted by the procedure described in Figure 1.

X-ray diffraction (XRD) experiments have been performed with a "Siemens D500o" diffractometer using $\mathrm{Cu}-K_{\mathrm{a}}$ radiation $\left(\lambda_{K a}=0.15406 \mathrm{~nm}\right)$ in a $\theta / 2 \theta$ configuration. A database on CD-ROM is used for searching and retrieving X-ray powder diffraction patterns.

For semiconducting or insulating solid crystals, the valence and the conduction bands are separated by an energy gap (Figure 2). When the crystal is submitted to ionising radiation (UV, X-ray, $\gamma \ldots$...), an electron-hole pair is formed in the valence band. The electron is free to travel through the conduction band and to fall into an electron trap. While, the hole travels through the valence band and falls into a hole trap.

After irradiation, the trapped charges may escape if the temperature of the crystal is raised and may recombine together on a centre, which de-excites by photon emission. If the heating rate of the sample is constant and if the emitted luminous intensity is measured using a photomultiplier tube (PMT) linked to a pico-ammeter, some peaks are observed. Their temperature position is characteristic of the trap nature and their intensity depends on concentrations of both the traps and the recombination centres.

For the irradiation, we expose the samples one minute under a UV lamp $(\lambda=253.7 \mathrm{~nm})$, or 5 min under a $\mathrm{W}$-target $(45 \mathrm{kV}, 2 \mathrm{~mA})$, at $-190^{\circ} \mathrm{C}$, and then we keep the samples two minutes in the dark. The samples are then heated at $60^{\circ} \mathrm{C} / \mathrm{mn}$ in the case of UV exposure, and at $30^{\circ} \mathrm{C} / \mathrm{mn}$ in the case of X-ray irradiation. The emission is then detected by a Hamamatsu R562 PMT with a spectral response between 160 and $850 \mathrm{~nm}$.

\section{Experimental results}

The TL of monoclinic zirconia has already been studied.[10, 11 and 12] Six peaks were found at $-170,-140,-85,-30,10$ and $110^{\circ} \mathrm{C}$, [12] (for a measurement at $30^{\circ} \mathrm{C} / \mathrm{mn}$ ) and one of them $\left(-30^{\circ} \mathrm{C}\right)$ was attributed to the presence of tetragonal zirconia, which is present as foreign phase in the sample of monoclinic zirconia [12 and 13].

Each pure oxide was studied by TL after UV irradiation, before and after the thermal treatment (Figure 3). One can notice that the studied $\alpha$-alumina presents no peak after UV irradiation. The monoclinic zirconia, which is used in this study, presents 6 TL peaks after UV 
irradiation situated at $-170,-145,-90,-35$, $\mathrm{O}$ and $95{ }^{\circ} \mathrm{C}$, but the peak at $-35^{\circ} \mathrm{C}$ disappears after the thermal treatment.

In the case of alumina-zirconia mixtures (before thermal treatment), we observe the same peaks as for pure zirconia, except the one at $-35{ }^{\circ} \mathrm{C}$ which does not appear. On the other hand, the peak at $-35{ }^{\circ} \mathrm{C}$ appears on the TL glow curve (Figure 4) obtained, after thermal treatment at $1400{ }^{\circ} \mathrm{C}$ under oxygen, from the same mixtures. Above $1170{ }^{\circ} \mathrm{C}$, the stable phase of zirconia is the tetragonal one. The presence of tetragonal zirconia in the powder is detected by XRD, for mixtures realised with an amount of zirconia higher or equal to $10 \mathrm{wt. \%}$ and treated at $1400{ }^{\circ} \mathrm{C}$ (Figure 5): XRD being not sensitive enough to detect tetragonal zirconia for lower amount of zirconia in the mixtures.

In order to verify that the peak at $-35^{\circ} \mathrm{C}$ is due to the presence of the tetragonal phase, some experiments were done:

Analyses achieved on mixtures by TL after X-ray irradiation, before and after the thermal treatment (Figure 6), lead to a glow curve presenting peaks of very weak intensity (150 times less intense than after UV irradiation). These peaks appear at the same temperatures than the peaks obtained under UV irradiation, and phenomena observed in that case (appearance of the $-35{ }^{\circ} \mathrm{C}$ peak after the thermal treatment) are similar to those described first. After X-ray irradiation, peaks would have been very intense if they were due to the alumina, this material being more sensitive to the X-ray than to the UV irradiation ( $\alpha$-alumina obtained under oxidant atmosphere, is not thermoluminescent after UV irradiation). Thus, it can be concluded that all the observed peaks, particularly that at $-35{ }^{\circ} \mathrm{C}$, are due to the zirconia.

We have also studied a commercial mixture (containing 10 vol.\% of $\mathrm{m}-\mathrm{ZrO}_{2}$ ), allowing the stabilisation of zirconia in tetragonal form after sintering. This mixture is prepared in the following manner: an alumina powder (>99.9 wt.\% purity) is homogeneously mixed with a monoclinic zirconia (> 99.9 wt.\% purity) in distilled water, with a conventional mixingmilling technique. Subsequently, they are spray-dried. The final size of the grains in the mixture was measured between 0.33 and $0.40 \mu \mathrm{m}$.

This mixture was characterised by TL and XRD, before and after the thermal treatment (with $1400^{\circ} \mathrm{C}$ under oxygen). Before the thermal treatment, we observe by TL (Figure 7) an intense peak at $-145{ }^{\circ} \mathrm{C}$, a peak towards $-50{ }^{\circ} \mathrm{C}$, and a peak at $\mathrm{O}^{\circ} \mathrm{C}$ which is probably the characteristic peak of monoclinic zirconia at $\mathrm{o}^{\circ} \mathrm{C}$. After thermal treatment, the peaks at -50 and $0{ }^{\circ} \mathrm{C}$ disappear, the one at $-145{ }^{\circ} \mathrm{C}$ decreases and the peak at $-35{ }^{\circ} \mathrm{C}$ appears.

We observe by X-ray diffraction the presence of the monoclinic phase. But after the thermal treatment, almost all the monoclinic zirconia disappears and we observe a strong prevalence of the tetragonal zirconia (Figure 8).

Complementary analyses were carried out on a mixture containing alumina with 5 wt.\% of cubic zirconia, and on pure cubic zirconia, before and after the thermal treatment. The cubic zirconia presents no peak in TL after UV irradiation. The TL of the mixture does not present emission either. We can thus conclude that the peak at $-35^{\circ} \mathrm{C}$ was not due to the presence of cubic zirconia.

\section{Discussion}

The thermal treatment of $\mathrm{a}-\mathrm{Al}_{2} \mathrm{O}_{3}-\mathrm{m}-\mathrm{ZrO}_{2}$ mixtures allows us to reveal the appearance of a peak at $-35^{\circ} \mathrm{C}$ by low temperature TL after UV irradiation.

This peak is not due to the presence of alumina as it is shown by the TL glow curve obtained after X-rays irradiation.

For the commercial mixture, the zirconia monoclinic phase disappearance, after the thermal treatment, coincides with the disappearance of the TL peak at $\mathrm{o}^{\circ} \mathrm{C}$, and with the appearance of an intense peak at $-35^{\circ} \mathrm{C}$. So this peak is not due to the presence of monoclinic zirconia.

After complementary experiments carried out with a cubic zirconia, for which no light emission by TL is observed, it is reasonable to attribute the appearance of the TL peak at $-35^{\circ} \mathrm{C}$ to the presence of tetragonal zirconia stabilised by the alumina. 
Furthermore the presence of the peak at $-35{ }^{\circ} \mathrm{C}$ in the thermogramme of the pure monoclinic zirconia (Figure 2), can be explained by the presence of tetragonal zirconia in our commercial monoclinic zirconia. Indeed, thermal treatment led to grain growth in zirconia. The grain size becomes higher than the critical size under which the zirconia remains tetragonal at ambient temperature. The small amount of tetragonal zirconia is thus transformed into monoclinic zirconia. Then the disappearance of the peak at $-35{ }^{\circ} \mathrm{C}$ in the thermogramme of the thermally treated powder is observed.

\section{Conclusion}

The presence of zirconia tetragonal phase stabilized by alumina can be detected in aluminazirconia composites by the thermoluminescence technique.

Moreover, the detection limit of this technique is appreciably better than with the X-rays diffraction technique. Indeed, for an amount of zirconia lower than $10 \mathrm{wt} \%$ in the composite, $\mathrm{XRD}$ does not allow to detect the presence of tetragonal zirconia, while the peak at $-35{ }^{\circ} \mathrm{C}$ is still appearing for only 1 wt.\% of zirconia by TL method.

\section{References}

[1] E.C. Subarao, H.S. Mati and Srivastava, Phase transformations in Zirconia. Phys. Status Solidi A 211 (1974), pp. 9-40.

[2] Bansal, G. K. and Heuer, A. H., On a martensitic phase transformation in Zirconia $\left(\mathrm{ZrO}_{2}\right):$ I, metallographic evidence. Acta Metall., 1972, 20(11), 1281-1289; II, crystallographic aspects. Acta Metall., 1974, 22(4), 409-417.

[3] G.M. Wolten , Diffusionless phase transformations in zirconia and hafnia. J. Am. Ceram. Soc. 469 (1963), pp. 418-422.

[4] S. Hori, M. Yoshimura, S. Somiya, R. Kurita and H. Kaji , Mechanical properties of $\mathrm{ZrO}_{2}$-toughened $\mathrm{Al}_{2} \mathrm{O}_{3}$ ceramics from CVD powders. J. Mater. Sci. Lett. 4 (1985), pp. 413-416.

[5] F.F. Lange and D.J. Green, Effect of inclusions size on the retention of tetragonal $\mathrm{ZrO}_{2}$ : theory and experiments. In: A.H. Heuer and L.W. Hobbs, Editors, Advances in Ceramics 3, Science and Technology of Zirconia, The American Ceramic Society, Columbus, OH (1981), pp. 217-225.

[6] F.F. Lange and M.M. Hirlinger, Hindrance of grain growth in $\mathrm{Al}_{2} \mathrm{O}_{3}$ by $\mathrm{ZrO}_{2}$ inclusions. J. Am. Ceram. Soc. 673 (1984), pp. 164-168

[7] A.H. Heuer, N. Claussen, W.M. Kriven and M. Rühle , Stability of tetragonal $\mathrm{ZrO}_{2}$ particles in ceramics matrices. J. Am. Ceram. Soc. 6512 (1982), pp. 642-650.

[8] N. Claussen and J. Jahn , Transformation of tetragonal $\mathrm{ZrO}_{2}$ particles in a ceramic matrix. Ber. Dtsch. Keram. Ges. 5511 (1978), pp. 487-491.

[9] M. Kagawa, M. Kikuchi, Y. Syono and T. Nagae , Stability of ultrafine tetragonal $\mathrm{ZrO}_{2}$ coprecipitated with $\mathrm{Al}_{2} \mathrm{O}_{3}$ by the Spray-ICP technique. J. Am. Ceram. Soc. 6611 (1983), pp. 751-754.

[10] J.F. Sarver J. Electrochem. Soc. 113 (1966), p. 124.

[11] C. Bettinali, G. Ferraresso and J.W. Manconi J. Chem. Phys. 50 (1969), p. 3957.

[12] P. Iacconi, D. Lapraz and R. Caruba , Traps and emission centres in thermoluminescent $\mathrm{ZrO}_{2}$. Phys. Stat. Sol. 50 (1978), pp. 275-283.

[13] G. Teufer Acta Crystallogr. 15 (1962), p. 1187. 


\section{Figures}

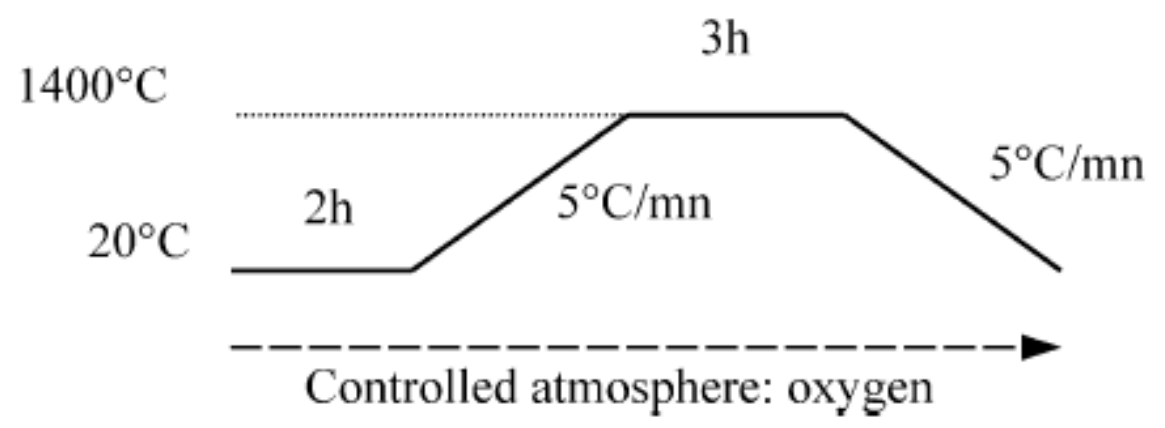

Figure 1:.Thermal cycle for the treatment of the a- $\mathrm{Al}_{2} \mathrm{O}_{3}-\mathrm{ZrO}_{2}$ mixtures.

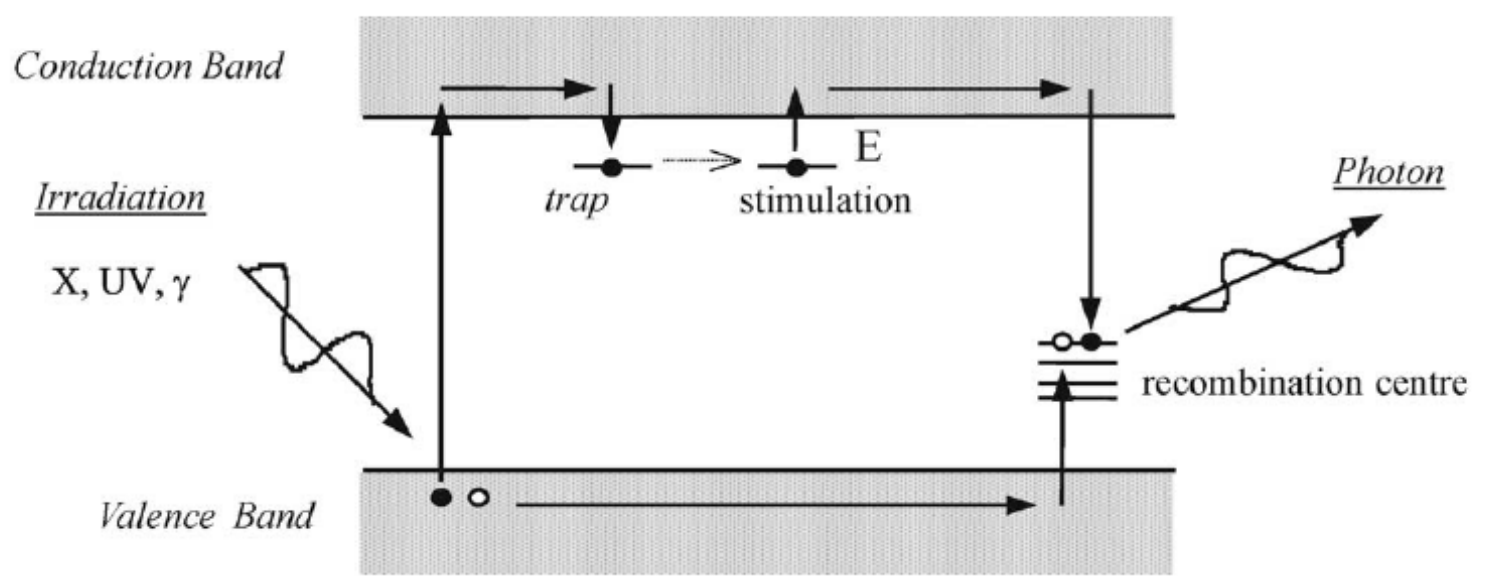

Figure 2: Schematic diagram of thermoluminescence mechanism.

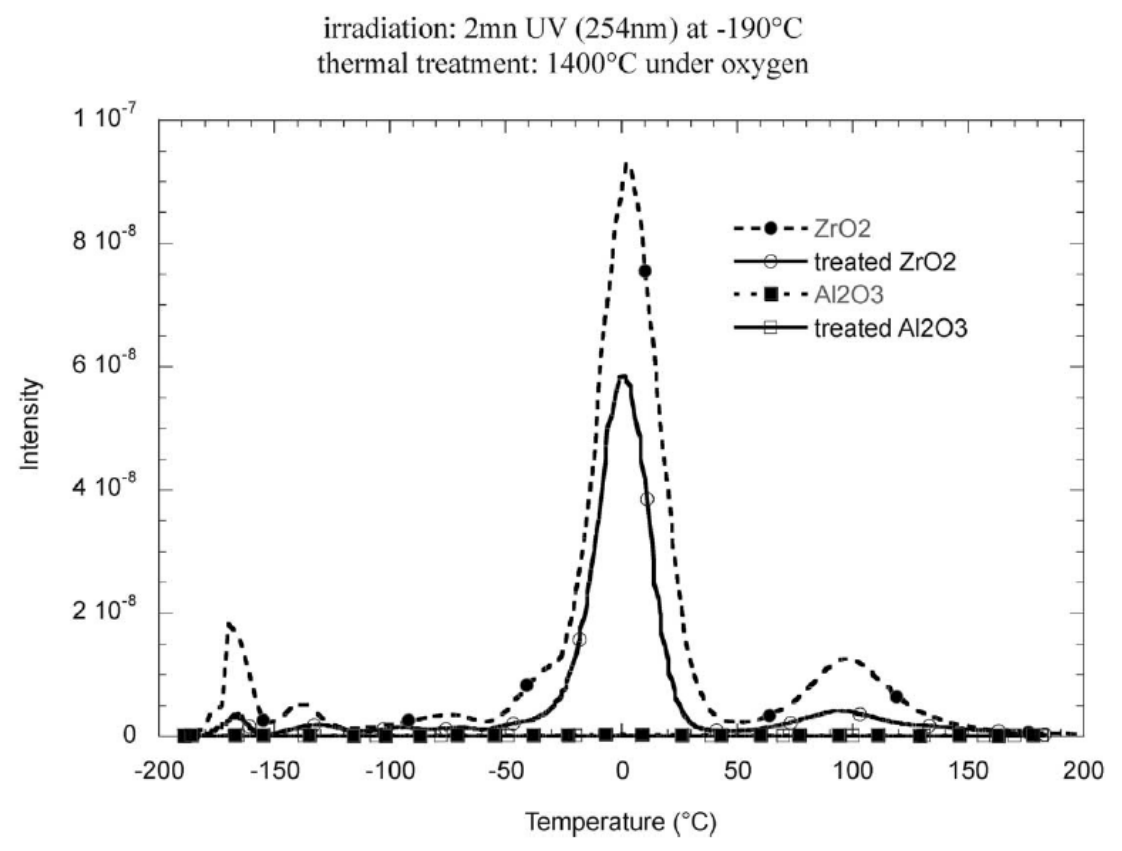

Figure 3: Thermoluminescence after UV irradiation of pure oxides before and after the thermal treatment at $1400 \_$Cunder oxygen. 

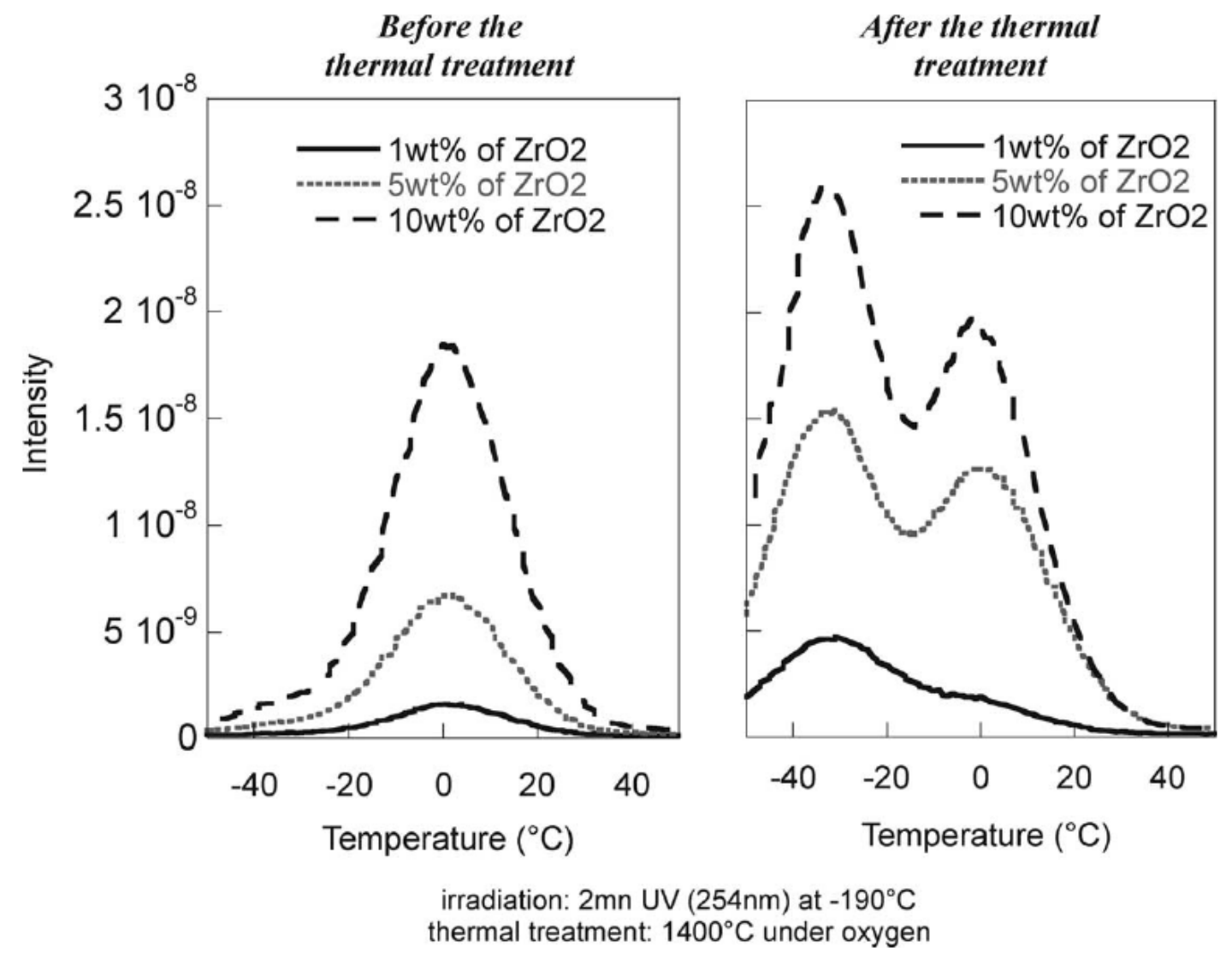

Figure 4: Thermoluminescence after UV irradiation of mixtures before and after the thermal treatment (for 1,5 and $10 \mathrm{wt} . \%$ of $\mathrm{ZrO}_{2}$ ).
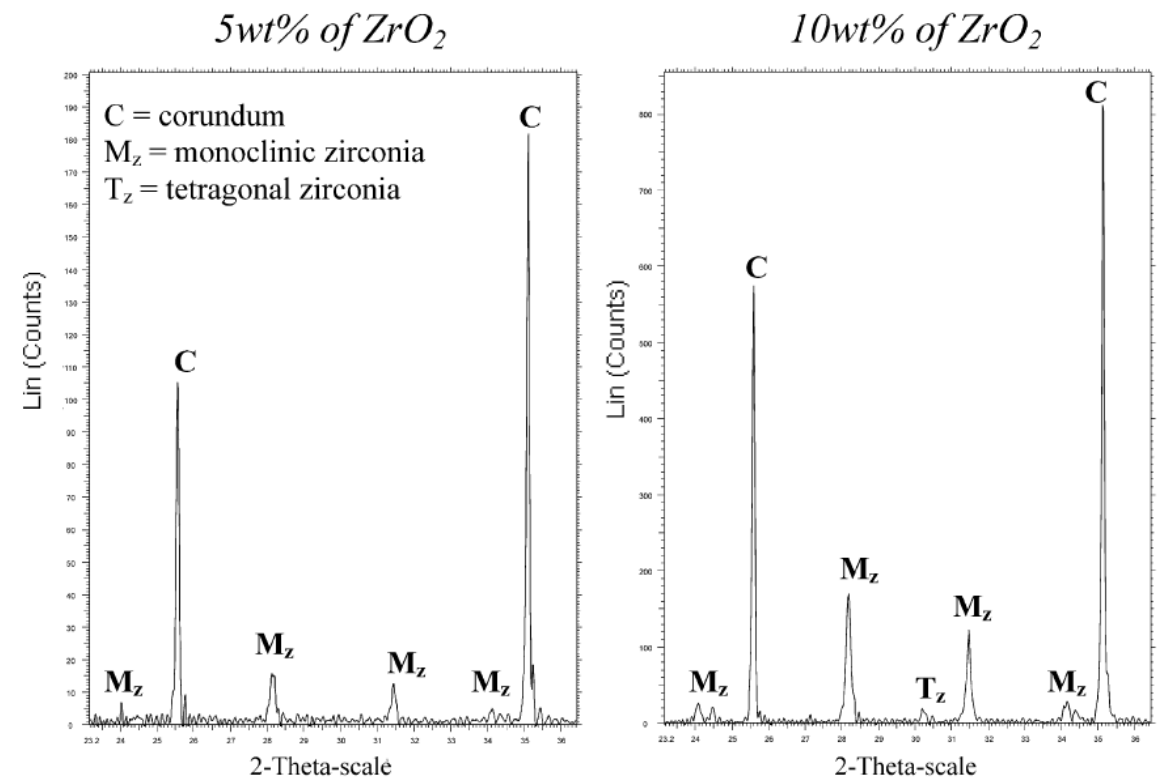

Figure 5: X-ray diffraction at room temperature of mixtures after the thermal treatment for amounts of 5 and 10 wt.\% of $\mathrm{ZrO}_{2}$. 


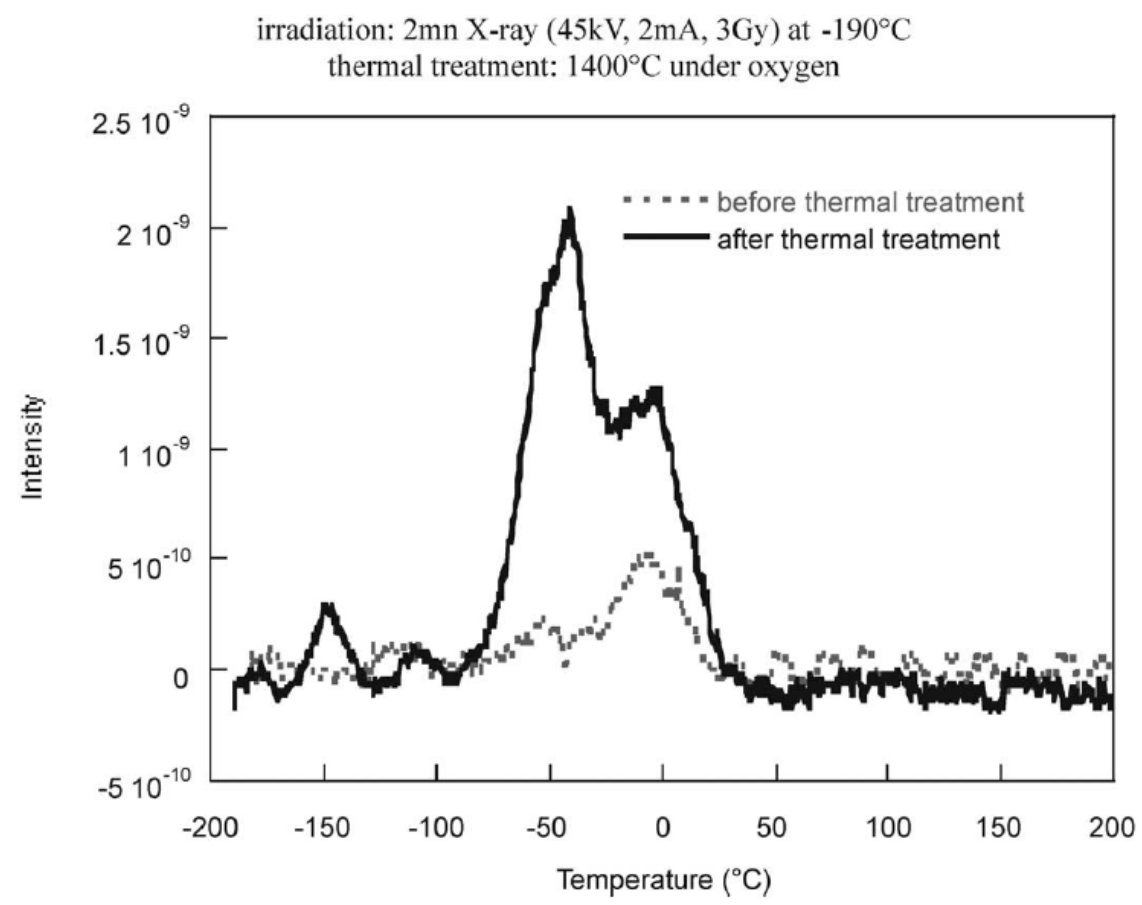

Figure 6: Thermoluminescence after $\mathrm{X}$-ray irradiation of the mixture containing $5 \mathrm{wt} . \%$ of $\mathrm{ZrO}_{2}$, before and after the thermal treatment.

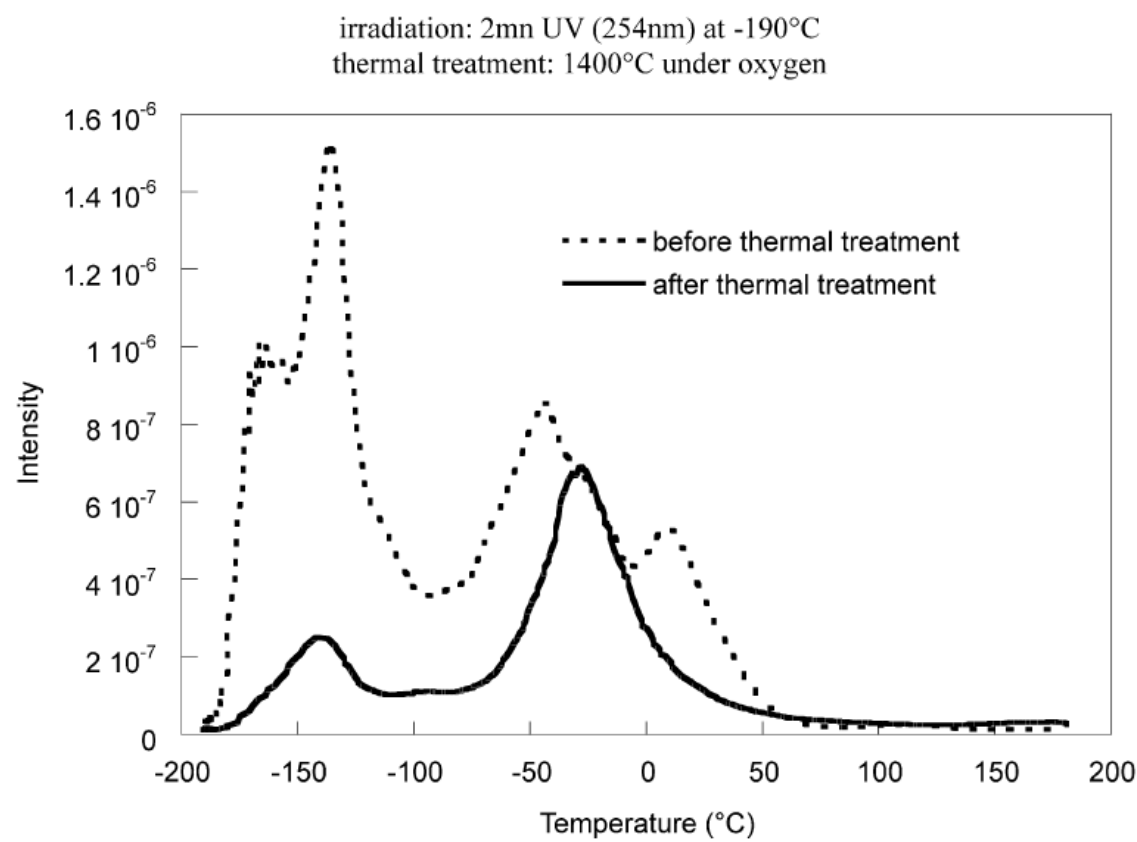

Figure 7: Thermoluminescence after UV irradiation of a commercial mixture (allowing the stabilisation of zirconia in tetragonal form after sintering), containing $10 \mathrm{vol} . \%$ of $\mathrm{ZrO}_{2}$, before and after the thermal treatment. 
Journal of the European Ceramic Society, 2003, 23(5), 667-73, doi:10.1016/So955-

2219(02)00161-9
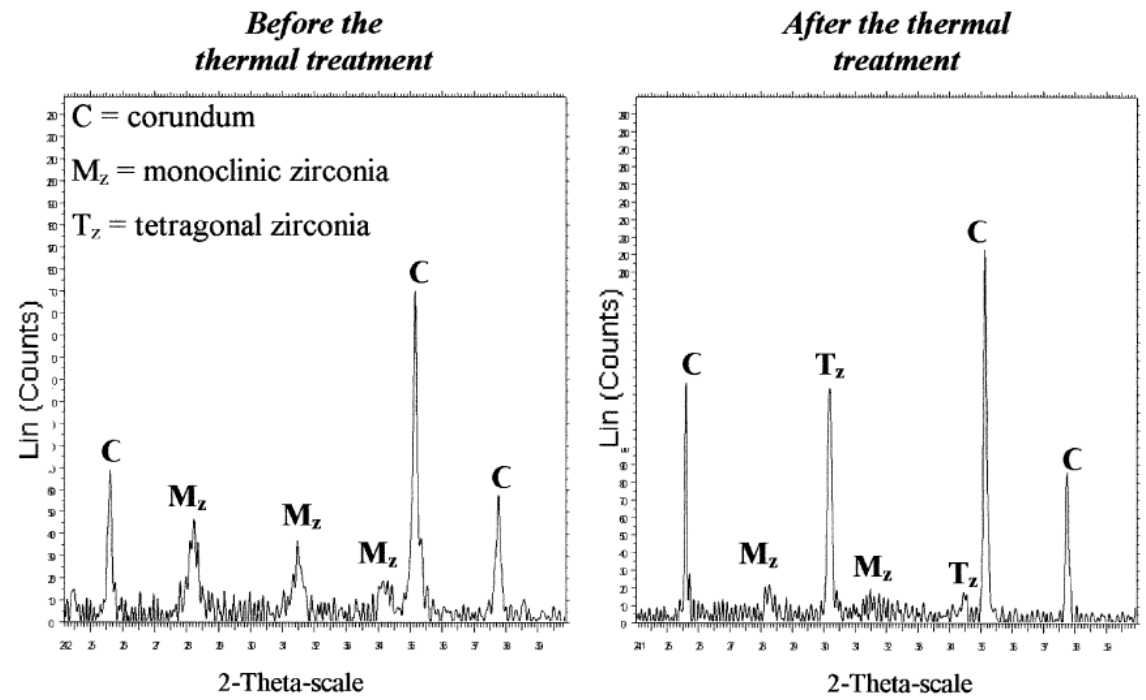

Figure 8: X-ray diffraction of the commercial mixture (10 vol.\% of $\mathrm{ZrO}_{2}$ ) before and after the thermal treatment. 